\title{
Simone de Beauvoir e a escrita dos feminismos
}

Há vinte anos Mariza Correa (1999) iniciava a apresentação do dossiê Simone de Beauvoir e os feminismos do século $X X$, publicado pela cadernos pagu, comentando que sua primeira reação foi pensar que talvez Simone não gostasse de homenagens, mas, frente à importância de sua obra, mais que as merecia.

Este dossiê parte dessa introdução, tão no estilo de Mariza e da convicção de que essa senhora, Simone de Beauvoir, continua merecendo muitas homenagens, pois sua obra multidisciplinar permite sempre novas leituras. Afinal, de fato ser mulher não é um fato da natureza e sim o resultado de uma história, como Simone reafirma em sua primeira entrevista televisiva, em $1975 .{ }^{1}$ Contudo, o maior interesse da entrevista é por ser esta a primeira em que Simone, então com 68 anos de idade, se declara inequivocamente feminista. Também é interessante notar que a própria entrevista de Simone provavelmente tinha relação com o fato de a questão da mulher ter entrado na pauta da ONU - e 1975 ter sido declarado o Ano Internacional da Mulher. No entanto, Simone, na sua modéstia, não se deu conta de que as lutas feministas que tornaram possível o Ano Internacional da Mulher resultavam, em grande medida, de sua obra teórica, especialmente de $O$ Segundo Sexo (1949).

Como é sabido, o livro instituinte dos feminismos modernos foi escrito por uma filósofa que não se considerava feminista, mas uma intelectual crítica da situação social da mulher de sua época. Se, mesmo já passados 70 anos, suas teses persistem, pode-se bem imaginar o impacto da obra de Simone de Beauvoir nos idos

\footnotetext{
1 O então jovem jornalista Jean Louis Servan-Schereiber é o entrevistador que compara o impacto da obra de Simone à obra de Karl Marx. E, enfatiza ele, aqueles que acharem desproporcional a comparação não se deram conta ainda da potência do movimento feminista.
} 
do pós-Segunda Guerra Mundial. Em 1999, em comemoração aos 50 anos do livro, a quantidade e a diversidade das publicações sobre a obra de Simone comprovaram uma espécie de renovação de sua leitura, grande parte dos estudos tendo-se aprofundado nas questões filosóficas levantadas em $O$ Segundo Sexo e outras obras de Simone, o que resultou no resgaste de sua originalidade como pensadora e na atualidade de seu conceito de "situação".

Continuando na mesma linha que soma homenagem a estudo, os artigos que compõem este dossiê não apenas comprovam a atualidade e a importância da obra de Simone de Beauvoir, como também a diversidade de leituras possíveis e o impacto existencial da obra sobre a vida de muitas de nós.

Fiel à problemática beauvoiriana do texto em seu contexto, o artigo de Heci Candiani (Unicamp), "O que pode ser criticado nas críticas ao $O$ Segundo Sexo", analisa a questão da recepção do livro na França e nos Estados Unidos dos anos 1950, mostrando os limites e os grupos de interesse que estiveram por trás da sua rejeição. Assim, busca-se compreender as condições sociais e históricas de produção dessas críticas, as relações de forças características dos meios intelectuais - principalmente na França, nos Estados Unidos e na Inglaterra - e "o modo como essas críticas estão associadas a um processo de silenciamento de Simone de Beauvoir". O renascimento do interesse por sua obra, principalmente a partir dos anos 1980, parte principalmente das leituras que privilegiam a dimensão filosófica do livro.

María Luisa Femenías (Universidad Nacional de La Plata, Argentina) explora a importância ética da obra beauvoiriana e sua originalidade, no artigo "Filosofia de la ambiguedad o el ambíguo lugar de las mujeres". Ela ressalta que, desde seus primeiros ensaios, o pensamento de Beauvoir diferencia-se do de Sartre em sua interpretação e no uso de conceitos como liberdade, projeto ou corpo, $e$ insiste em que é na sua dimensão moral que a existência humana se assume verdadeiramente como humana. Assim, a originalidade do pensamento de Simone a diferencia dos demais existencialistas e a qualifica como uma autêntica filósofa do século XX. 
Teresa López Pardina (Universidad de Madrid) também enfatiza a singularidade do existencialismo de Beauvoir, entendido como uma espécie de modulação que tem como consequência um outro olhar sobre o mundo, pois engloba dimensões da realidade que não haviam sido levadas em conta pelas demais correntes existencialistas. A seu sentir, a originalidade de Beauvoir é bastante evidente em relação às teorias filosóficas de seu tempo, mesmo que se servindo de princípios existencialistas $e$ fenomenológicos.

Karen Vintges (University of Amsterdam) discorda da leitura de Nancy Fraser, representante da vertente neoliberal do feminismo norte-americano, que enfatiza a dimensão de autonomia dos feminismos, desligando-os dos problemas das classes sócias e reforçando os pressupostos neoliberais. Em "Feminism versus neoliberalism: women's freedom practices in world perspective", Vintges lembra que a dimensão essencial do feminismo, nos seus primórdios, foi a da solidariedade $e$ participação democrática e que a deturpação de correntes identitárias que insistem na dimensão da exclusiva autonomia individual não pode, de maneira alguma, ser atribuída aos pressupostos liberais de Simone de Beauvoir, a leitura de Frazer deixando de lado a dimensão libertária e solidária do feminismo.

Carla Rodrigues (PPGF/IFCS/UFRJ e Faperj), em seu artigo "Beauvoir relida por Butler - questões hegelianas e póshegelianas", tendo como ponto de partida a questão do sujeito, recupera as leituras de Hegel na França dos anos 1940/1950, examinando a questão da passagem da consciência natural para a consciência de si. Beauvoir questiona a possibilidade de que a interdependência entre homens e mulheres possa ser análoga à estabelecida por Hegel na relação entre o senhor e o escravo. Nessa crítica, opera uma distinção importante entre atividade $e$ função, para pensar o problema da biologia como destino. Sustenta-se a hipótese de que Beauvoir entra para a história da filosofia como a primeira pensadora a indicar não haver roteiros de subjetivação para contemplar a constituição da mulher como sujeito. $\mathrm{Na}$ leitura de Butler, em Beauvoir há ainda uma 
contradição que continua a operar na teoria feminista: o sujeito universal é entendido como masculino e tomado como referência, o que exclui as mulheres; ou a mulher é incluída nessa universalidade abstrata, o que exige descorporificar o sujeito masculino abstrato, sem que a mulher possa se tornar um sujeito de sua própria corporeidade.

Os demais artigos partem do extraordinário impacto que a leitura de Simone de Beauvoir significou na vida de toda uma geração que lá encontrou munição para enfrentar os discursos $e$ comentários machistas, ajudando-nos a entender nosso próprio mal-estar. Assim, há uma recepção no campo intelectual e outra mais situada no campo existencial, considerando-se tudo que o livro e o estilo de vida de Simone abriram como perspectiva.

Carmen Barroso (Co-Chair of the Independent Accountability Panel appointed by the UN), em "As ideias e os ideais que definem uma vida: Simone de Beauvoir e Carmen da Silva", confessa que, das suas várias identidades, há uma que é central: a de feminista, e que foi a partir das ideias da filósofa francesa e da cientista social brasileira que ela conseguiu pôr em palavras o inconformismo e a rebeldia que a acompanhavam desde muito cedo. Para o debate atual, não obstante transformações imensas no período que nos separa da publicação de $O$ Segundo Sexo, ela afirma que algumas questões básicas continuam não resolvidas. Seu artigo focaliza, sobretudo, o papel da mulher na reprodução da espécie e os obstáculos que ainda se interpõem à maternidade livre, especialmente o acesso à contracepção e ao aborto.

Magda Guadalupe dos Santos (PUC Minas - FaE/UEMG), no artigo intitulado "Os desafios da escrita por 'encomenda' e o esforço de desmitificação no pensamento de Simone de Beauvoir", investiga a relação argumentativa de tópicos de $O$ Segundo Sexo, publicado em 1949, com os escritos "encomendados" por editores norte-americanos, como o texto intitulado Brigitte Bardot e a síndrome de Lolita, lançado em primeira edição em agosto de 1959. Entende que há de comum entre eles a proposta de desmitificação, presente nos escritos 
teóricos e inclusive nos nomeados autobiográficos. Em todas as situações, ela entende que Beauvoir discute temas relevantes como simetria, identidade e diferença, tanto entre culturas - da Europa às Américas -, quanto entre os sexos - na complexa relação do feminino, criticado em bases de suposta "natureza" das mulheres, e o masculino, que se destaca na sociedade patriarcal. Não se trata, para Beauvoir, de reverter, pela escritura, os dilemas da história, mas de criticar o impacto da cultura na leitura e na escritura do real, sem se resignar a arbítrio e imposições. O teor axiológico presente nos escritos "encomendados" é o mesmo que se configura em $O$ Segundo sexo, no esforço de desmitificar as ilusões que sobrevoam a realidade histórica, o método de análise em Beauvoir podendo ser tomado como uma matriz dos feminismos contemporâneos.

Mónica Tarducci (UBA, Argentina), no artigo "Todas queríamos ser como Simone'. Las primeras lecturas de El Segundo Sexo en Argentina", busca rastrear o impacto do livro, assim como do estilo de vida de Beauvoir, nada convencional para a época, o qual influenciava a recepção da obra. Entende que Simone de Beauvoir e Jean-Paul Sartre constituíam um casal "livre" (liberdade que também aparecia nas obras de Beauvoir), já que eram comunistas, visitavam Cuba, eram anti-imperialistas e a favor da independência da Argélia. Os círculos intelectuais na Argentina, inclinados à admiração da cultura francesa, seguiam as discussões sartreanas e muitos e muitas se denominavam existencialistas. Tarducci realça ser impossível separar a vida da obra de Beauvoir, mostrando como tal fato aparece nos relatos das mulheres que leram $O$ Segundo Sexo em épocas anteriores à nossa.

Finalmente Maíra Kubík Mano (PPGNEIM/UFBA-Bahia), no artigo "As mulheres desiludidas: de Simone de Beauvoir à 'ideologia de gênero'", examina como, em 2015, Beauvoir foi alvo de uma moção de repúdio da Câmara Municipal de Campinas, acusada de ser a mentora da chamada "ideologia de gênero", expressão utilizada pelo campo conservador para confrontar as produções científicas acerca dos papéis sociais masculinos $e$ 
femininos em relação com as desigualdades e hierarquias deles derivadas. Argumentações semelhantes foram utilizadas em diversas casas legislativas estaduais e municipais, para não apenas barrar a inclusão de gênero e sexualidade nos planos de educação, como para impedir o ensino de temáticas correlatas. A autora indaga por que, após 70 anos, "tornar-se mulher" segue sendo uma frase tão provocativa e até mesmo perigosa? Os medos e críticas que ela provocava então seguem sendo os mesmos ou estaríamos diante de um novo pânico moral? $\mathrm{O}$ artigo procura refletir sobre como tais argumentos $e$ movimentações parlamentares, como parte significativa do processo de fascistização social e política vivido pelo Brasil, têm em Beauvoir um de seus principais alvos.

Esperamos que este dossiê resulte numa reflexão sobre o processo de transformação percorrido pela cultura e que os tempos sombrios vivenciados em algumas situações da história possam ser também problematizados no confronto com ideias $e$ textos que tornam os feminismos signos de grande expressividade social e política. Para além de seu referencial teórico, os artigos que compõem este dossiê demonstram como $O$ Segundo Sexo repercute nos feminismos contemporâneos, assim como suas sucessivas aplicações nas análises da cultura provocam impacto nas mudanças de mentalidade.

\section{Maria Lygia Quartim de Moraes*** Magda Guadalupe dos Santos***}

\footnotetext{
** Professora do Departamento de Sociologia; pesquisadora do Núcleo de Estudos de Gênero-Pagu, ambos na Unicamp, Campinas, SP, e Professora Visitante da Unifesp-Campus Baixada Santista, Santos, SP, Brasil. maria.quartim@pq.cnpq.br / orcid.org//0000-0001-6132-1930

*** Professora de Filosofia da PUC Minas e da Faculdade de Educação da Universidade do Estado de Minas Gerais (FaE - UEMG). Pesquisadora de Filosofia e Teorias Feministas. Integrante de Simone de Beauvoir International Society. Integrante do GT ANPOF Desconstrução, Alteridade e Linguagem. magda.guadalupe@yahoo.com.br / https://orcid.org/0000-0001-6894-0654
} 


\section{Referências bibliográficas}

BEAUVOIR, Simone de. Le Deuxième sexe. Paris, Gallimard, 1976 (Folio). [1949]

BEAUVOIR, Simone de. O Segundo sexo. vol. I. Fatos e Mitos. Rio de Janeiro, Nova Fronteira, 1980. Tradução de Sérgio Milliet. [1949]

BEAUVOIR, Simone de. O Segundo sexo, vol. II. A experiência vivida Rio de Janeiro, Nova Fronteira, 1980. Tradução de Sérgio Milliet. [1949]

CORRÊA, Mariza. Apresentação. cadernos pagu (12), Campinas, SP, Núcleo de Estudos de Gênero-Pagu/Unicamp, 1999, pp.07-10. 